\title{
PREVALENCE OF IRON DEFICIENCY ANEMIA AMONG ADOLESCENT GIRLS AND ITS RISK FACTORS IN TANGAIL REGION OF BANGLADESH
}

\author{
Md. Shamim Miah", M. Nannur Rahman ${ }^{2}$, UK Prodhan ${ }^{2}$, MR Linkon ${ }^{2}$, Madumita ${ }^{4}$, Md. Sidur \\ Rahman $^{5}$ \\ ${ }^{1}$ MS Research Student, Department of Food Technology and Nutritional Science, Mawlana Bhashani Science and \\ Technology University, Santosh, Tangail-1902,Bangladesh.bscmsfn@gmail.com \\ ${ }^{2}$ Assistant Professor, Department of Food Technology and Nutritional Science, Mawlana Bhashani Science and \\ TechnologyUniversity, Santosh, Tangail-1902,Bangladesh.mnannuiu@gmail.com,utpalftns@yahoo.com \\ ${ }^{3}$ Lecturer, Department of Food Technology and Nutritional Science, Mawlana Bhashani Science and Technology \\ University, Santosh, Tangail-1902, Bangladesh.murtaja.kus@gmail.com \\ ${ }^{4}$ Research Assistant, Department of Biochemistry and Cell Biology of Bangladesh University of Health Sciences, \\ Bangladesh.lipi_khan06@yahoo.com
}

${ }^{5}$ Nutritionist,_BIRDEM General Hospital Shabagh, Dhaka. saidur.rahman@yahoo.com

\begin{abstract}
Anemia is a significant public health problem in Bangladesh especially in developing countries, affecting the lives of many children, adolescents and women every year. Over the last four decades, data on the prevalence of anemia indicated high in adolescents, without any trend for improvement. Thus the Author undertakes to assess the prevalence of iron deficiency anemia and its associated risk factors among adolescent girls. A cross sectional survey was conducted among adolescent girls selected purposively from different non government High School. Hematological parameters, Body Mass Index (BMI), Socioeconomic, demographic and related risk factors were obtained by a well defined questionnaire and appropriate biochemical method. There were $17.5 \%$ girls were suffering from iron deficiency anemia. Among them $0.8 \%$ severe, $5.8 \%$ moderate and $10.9 \%$ were mild anemic. In this study $31.82 \%$ and $9.21 \%$ found anemic in joint and nuclear family. Most of anemic patients found in the family whose family member more than 8. About $66.67 \%$ anemic adolescents were identified whose family's monthly income less than 6000 TK. About 23.08\% anemic respondent's parents were illiterate. There was a strong relationship between BMI (Body Mass Index) and anemia. The $P$ value of the association was 0.038 is statistically significant. Most of the respondents about $85.8 \%$ had no idea about iron deficiency anemia. Most of the anemic were found 5 days or more menstrual blood flow. All the anemic girls usually intake $5.21 \mathrm{mg}$ irons per day that is not available to meet the daily requirement. So it is essential to increase awareness about taking more iron during adolescent period to reduce the prevalence of anemia.
\end{abstract}

Keywords: Anemia, Adolescent Girls, Body Mass Index, Iron, Public Health.

\section{INTRODUCTION}

Adolescence, defined by World Health Organization (WHO) as the period between 10 and 19 years, is an important, formative time which shapes the future of boys' and girls' lives [1]. There are about 1.2 billion adolescents in the world, which is equal to $1 / 5$ th of the world's population and their numbers are increasing. Out of these, 5 million adolescents are living in developing countries [2]. There are 28 million adolescents in Bangladesh 13.7 million of them are girls and 14.3 million boys. In our country around 12 percent of the whole populations are adolescent girls. Bangladesh is a society of poor economic infrastructure with male biased social pattern which makes adolescent female a vulnerable group for nutrient deprivation [3]. Adolescence is a "coming of age", as children grow into young adults.
Adolescence is a particularly unique period in life because it is a time of intense physical, psychosocial, and cognitive development. Increased nutritional needs at this juncture relate to the fact that adolescents gain up to $50 \%$ of the weight, more than $20 \%$ of their adult height, and $50 \%$ of their adult skeletal mass during this period. The main nutrition problems affecting adolescent populations worldwide include under nutrition in terms of stunting and thinness, catch-up growth, and intrauterine growth retardation in pre adolescent girls, iron deficiency and anemia, iodine deficiency, vitamin A deficiency, calcium deficiency, other specific nutrient deficiencies, e.g. zinc, folate and obesity. Iron deficiency anemia (IDA) constitutes the major anemia during adolescent period. Accelerated development, hormonal changes, malnutrition and starting of menstrual periods in girls are major causes in this period. 
Because iron is an essential element for the function of various organs, its deficiency may lead to impaired perception and learning difficulties ending up with declined school success. In adolescent, the most frequent cause of megaloblastic anemia is the deficiency of vitamin $B_{12}$ and folic acid. Fresh vegetables and fruits contain folic acid, but the only source of vitamin $B_{12}$ is foods of animal origin. Deficiency of vitamin $B_{12}$ may cause neuropsychiatric problems, impaired behavior, lack of attention, learning difficulties and a decline in the success of the affected students [4]. In developing countries, factors associated with under nutrition of adolescents are: poor household economic condition, periodic food-shortage, child-labour (marker of household income-poverty), burden of disease, poor knowledge about long-term consequences of under nutrition of adolescents, quantity and quality of food, and access to health and nutrition services [5]. In Bangladesh, low family income, education, and periodic food-shortage were associated with inadequate dietary intake which might have led to under nutrition [6]. Dietary knowledge and access to resources are critical to improve health and nutrition in a sustainable way. Adolescence is the time to learn and adopt healthy habits to avoid many health and nutritional problems later in life Adolescents have more easy access to health and nutrition information through schools, recreational activities, and mass media than they have later in their lives Particularly, health and nutrition knowledge and healthy habits of female adolescents will have critical roles to play in maintaining future family health and nutrition [5]. Nutritional deficiencies have far reaching consequences in adolescent girls. If their nutritional needs are not met, they are likely to give birth to undernourished children, thus transmitting under nutrition to future generations [7]. The nutritional anemia in adolescent girls attributes to the high maternal mortality rate, the high incidence of low birth weight babies, high prenatal mortality and the consequent high fertility rates. This phase of life is also important due to the ever-increasing evidence that the control of anemia in pregnant women can be more easily achieved if a satisfactory iron status can be ensured during adolescence [8]. About $43 \%$ of the adolescent deaths are related to pregnancy. Pregnancy during adolescence deprives the girls from achieving their full growth according to their genetic potential [9]. One way to break the intergenerational cycle of malnutrition is to improve the nutrition of adolescent girls prior to conception. The vicious cycle of malnutrition, if not broken, will goes on resulting in more and more severe consequences [10]. Iron deficiency anaemia is considered to be the main type of anaemia among young children in Bangladesh due to poor dietary iron intake. This study, therefore, is aimed at assessing the prevalence of anaemia and its risk factors as we can create awareness among people.

\section{MATERIALS AND METHODS}

\subsection{Study Design}

A Purposeful Sampling Technique was used to select girls schools from where sample was selected by lottery method. A total number of 120 adolescent girls were selected from different Non- government school of Tangail district in the age group of 12-17years in order to arrive at dependable conclusion

\subsection{Development of Questionnaire}

A questionnaire was developed containing both closed \& open ended questions to obtain relevant information on anthropometric, socioeconomic, dietary condition of the adolescent girls. All questions were designed, pretested, modified and resettled to obtain and record information easily. Any modification necessary were then made and a final recoded, pretested questionnaire was drawn up.

\subsection{Anthropometric Assessment}

The anthropometric data were collected based on standard methods. Ages of the respondents were recorded from the registration book of school. Measurements of weight and height were obtained from all subjects. The subjects were weighed wearing minimal cloths and bare footed. Three weight measurements were obtained using a bathroom weighing scale and the average was calculated and recorded to the nearest $0.1 \mathrm{~kg}$. The height was measured with a wooden measuring board without shoes and the average was calculated and recorded to the nearest $0.1 \mathrm{~cm}$. Body Mass Index (BMI) as the best method of measuring the nutritional status of adolescent girls.

$$
\mathrm{BMI}=\frac{\text { Weightin } k g}{\text { Height in } \mathrm{m}^{2}}
$$

\subsection{Socio-Demographic Data}

Information on demographic and socioeconomic variables was obtained by a structured standard questionnaire.

\subsection{Clinical and Bio-Chemical Assessment}

Clinical examination is the most essential part of all nutrition surveys, essentially the method is based examination the subject for changes, believed to be related various nutrient deficiency that can be seen or felt in superficial epithelial tissues especially skin, eyes, hair, tongue, teeth etc. The Hemoglobin estimation of the all 120 sample was done in collaboration with well reputed clinical laboratory (Sahli's method). The reading was compared with WHO standards for classification of anemic samples.

\subsection{Menstrual History}

This section pertained to the menstrual history of the respondents. The questions included in this section were menopausal syndrome, duration of the blood flow \& interval between the next menstrual cycles.

\subsection{Dietary Behavior Assessment}

24 hour recall was used to obtained information regarding the intake of different nutrients such as calories, proteins, calcium, fat and iron. In this the quantity of food consumed by the respondents in terms of household measures (cup, 
spoons, ladles, serving spoons, katories, plates etc) was recorded. Subjects were asked to recall the actual food consumed during last 24 hours and this was recorded on the diet sheet. The quantity was measured through these standardized containers. These were later converted into metric weight and the nutritive value was calculated using food consumption table.

\subsection{Data Analysis}

The data set were first checked, cleaned and entered into the computer from the numerical codes on the form. The data was edited if there is any discrepancy and then cleaned it. The frequency distributions of the entire variables were checked by using SPSS 16.0 windows program. For tabular, charts and graphical representation Microsoft word and Microsoft excel were used.

\section{RESULTS AND DISCUSSIONS}

\subsection{Socio-Demographic Features of the Respondent}

In this cross sectional study a total of 120 adolescent girls were attend for the studied. The mean age (years, mean \pm SD) of those participants was $13.9667 \pm 1.230$. Among the participants $12.5 \%$ participants were 12 years, $25.0 \%$ participants were 13 years, $30.8 \%$ participants were 14 years, $18.3 \%$ were participants 15 years, $11.7 \%$ participants were 16 years and $1.7 \%$ participants were 17 years old. The level of education $30.83 \%$ of both father and mother were illiterate, and $42.50 \%$ of them were single literate and $26.67 \%$ of both father and mother were literate. All respondent's family size was divided into 4 groups. Among them $11.6 \%$ had up to 3 members in their family, $34.2 \%$ had 4-5 members in their family, $36.7 \%$ had 6-7 members in their family and $17.5 \%$ had more than 8 members in their family. All respondent's family had divided into 2 groups. Among them $63.3 \%$ were nuclear family and $36.7 \%$ were joint family. Table 1 also shows that among 120 respondents only $0.8 \%$ were severe anemic, $5.8 \%$ were moderate anemic, $10.9 \%$ were mild anemic and the rest $82.5 \%$ respondents were non-anemic. While questioning about the problem of iron deficiency $85.8 \%$ of participants answered no i.e. they had no idea about the problem of iron deficiency and the rest of $14.2 \%$ participants answered yes that means they had idea about the problem of iron deficiency.

\subsection{Relationship of Anemia with Certain Condition}

\section{of the Respondent}

The distribution of respondents according to their type of family is shown in Table 2 the nuclear family setup has emerged as the main pattern of families during current years thus vanishing the joint setup. Within group analysis table shows that majority 31.82 percent of girls in the anemic group were belonging from Joint type of family, whereas in the normal group respondents were distributed as $90.79 \%$ nuclear family. The association between the two groups with respect to type of family was found statistically significant as the $p$ value $(p=0.014)$ is less than the level of significance 0.05 . The family size plays an important role in dietary intake of individuals. Table 2 envisages that almost 38.10 percent of the respondents having anemia were from the families having family size of more than eight members. A gradual decrease in percentage of anemic girls was seen in groups as the family size gets reducing. Significant association was found between two groups and the family size, suggesting that both the groups are effected by family size $(p=0.045)$. The table 2 shows that the numbers of anemic is higher in low income group, but at the same time normal are also equally high in this income group. A slight difference in percentages cannot be taken as significant which is evident from chi-square value and $p$ value $(p=0.000)$ of the test of association. It is common belief that educated parents are conscious of giving their children the requisite and balanced diet. Almost $24.53 \%$ of the girls among anemic group were those having both the parents illiterate and $3.57 \%$ were respondents in the anemic group whose parents were literate. It can also be seen from the table that there is decline in percentage of anemic girls when both the parents are illiterate as against when at least one of them is literate. Inter group comparison shows that in totality the highest percentage $24.53 \%$ of anemic respondents had parents illiterate. To justify the fact statistically, whether educational status of parents does influence the anemic condition, chi-square test was employed which shows that there is significant association $(p=0.021)$. Further, in case of anemic group the lowest percentage i.e, $7.40 \%$ had duration of blood flow of 2-3 days and highest percentage i.e $35.48 \%$ had duration of blood flow for more than 5 days. In case of normal group, lowest percentage i.e $64.52 \%$ the duration of blood flow more than 5 days. Table 2 also shows consumption of milk, fruits and green leafy vegetables by the respondents. In anemic group the lowest percentages i.e $4.76 \%, 19.05 \%$ and $14.29 \%$ consumed milk or milk based products, fruits and green leafy vegetables daily. The highest percentages among anemic group i.e $61.91 \%, 57.14 \%$ and $52.38 \%$ consumed milk or milk based products, fruits and green leafy vegetables irregularly.. In order to ascertain whether there is any association between the two groups with respect to the consumption of milk or milk based products, fruits and green leafy vegetables by the respondents, chi-square test was employed which show that there is statistically significant association $(\mathrm{p}=0.018, \mathrm{p}=0.028$ and $\mathrm{p}=0.003)$ between the two groups.

The figure 1 describes the body mass index of respondents studied. The lowest percentage of anemic group i. e $9.21 \%$ (exception $0 \%$ ) belongs to ideal weight category and highest percentage i. e $35.90 \%$ belongs to underweight category. While same observations were found in normal group, the lowest percentage i. e $64.10 \%$ belongs to underweight groups and highest percentages i. e $100 \%$ and $90.79 \%$ belongs to overweight and normal groups. In order to ascertain whether there is any association between the two groups with respect to their Body Mass Index (BMI) chi-square test was employed which shows that there is statistically significant association $(p=0.038)$ between the two groups. 


\subsection{Relation between Anemia and Nutritional}

\section{Intake of Respondents as per 24 Hours Dietary}

\section{Recall}

The data presented in table 3 show the nutrient intake among respondents of various age groups (13-17 years). The caloric intake of normal group was $1622 \mathrm{kcal}$ and for anemic group was almost same $1592 \mathrm{kcal}$. Interval variation was not much as given by the values of standard deviation of two groups' i. e, 255 kcal 293 kcal respectively. Comparison of mean caloric intake by respondents and prescribed value by RDA show difference is insignificant across all age groups. The overall mean iron intake in case of anemic group $5.21 \mathrm{mg}$ while as that of the normal respondents was $7.05 \mathrm{gm}$ in both the cases intake is much lower than RDA values. Where in $28 \mathrm{mg}$ /day is prescribed for the age group of 13-15 years while as for 16 years of age it is $30 \mathrm{mg} / \mathrm{day}$. Hence the difference significant as is evident by $\mathrm{p}$ values also.

\section{CONCLUSIONS}

From the present study it was revealed that anemia is a major health problem among adolescents especially girls. Because of lack of proper information regarding dietary habits adolescents have a habit of skipping their meals because they are more conscious about their body structure. It has been found that result of heavy periods and reduced iron intake. Prevalence of anemia in adolescent girls is high $(34.21 \%)$ in underweight participants. The Results of this study show that the factors such as age, literacy status of parents, type of family, weight, diet, frequency of intake of green leafy vegetables and fruits, and menstrual discharge are the factors contributing to the prevalence of anemia. Clinical examination showed that girls had signs of various deficiencies. BMI of adolescent girls was less than the standard. The intake of all the nutrients was found less than recommended dietary allowances. So, govt. should promote awareness programs in schools which will lead to healthy eating patterns and selection of appropriate foods. They should also be given education about enhancing factor intake of vitamin $\mathrm{C}$ which helps in the absorption of iron.

\section{REFERENCES}

[1]. World Health Organisation (2000). Young People's Health-A Challenge for Society. Report of a WHO Study Group on Young People and Health for All by the Year [2]. Mathur J.S.S. (2007). Preventive and Social Medicine, A comprehensive text book.1st ed. New Delhi: CBS Publishers and Distributors; 382-89.

[3]. UNICEF (2008). Adolescent Empowerment Project in Bangladesh

[4]. Yasemin I. B., Karabulut M.A., Gurses M.D., Pediatr I.J. (2012). Prevalence and Risk Factors of Anemia among Adolescents in Denizli, Turkey, March; 22(1): 77-81.
[5]. Kurz K.M. and Welch C. (1994). 'The nutrition and lives of girls in developing countries: findings from the nutrition of adolescent girls research program. Washington, DC: International Center for Research on Women .

[6]. Abdullah M. and Wheeler E.F. (1985) 'Seasonal variations and the intra-household distribution of food in a Bangladeshi village'. Am J Clin Nutr. 41:1305-13.

[7]. Naeya R.L. (1981). Teenaged and pre-teenage pregnancies consequences of the fetal maternal competition for nutrients Paediatrics; 67:146-150.

[8]. Kaur S., Deshmukh P.R., Garg B.S. (2006). Epidemiological correlates of nutritional anaemia in adolescent girls of rural Wardha. Indian J Community Med; 31:255-58.

[9]. Pathak P., Singh P., Kapil U., Raghuvanshi R.S., (2003). Prevalence of iron, vitamin A and iodine deficiencies amongst adolescent pregnant mothers. Indian J Paediatr; 70: 299-301.

[10]. Brabin L. and Brabin B.J. (1992). 'The cost of successful adolescent growth and development in girls in relation to in relation to iron and vitamin A status' $A m J$ Clin Nutr; 55:955-958.

\section{BIOGRAPHIES}

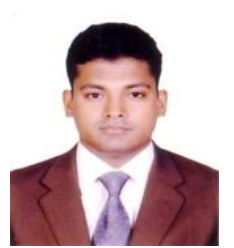

The author is Assistant Professor in the department of Food Technology and Nutritional Science of Mawlana Bhashani Science and Technology University, Bangladesh. He has completed four years graduation B.Sc with honors and M.Sc in Applied Nutrition and Food Technology from Islamic University, Bangladesh with First Class and placed 2nd position. He has almost 6 years of teaching experience and is currently supervising 19 Master's Thesis students and 12 Undergraduate students. $\mathrm{He}$ has a national research connection with different research organizations of Bangladesh and has several publications in the field of Food and Nutrition

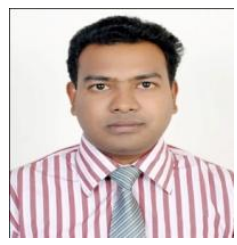

The author is a Lecturer in the department of Food Technology and Nutritional Science of Mawlana Bhashani Science and Technology University, Bangladesh. He has completed four years graduation B.Sc with honors and M.Sc in Applied Nutrition and Food Technology from Islamic University, Bangladesh with First Class and placed 1st position. He has almost 2 years of teaching experience and 3 years working experiences with development organization and is currently co-supervising 3 Master's thesis students and 8 Undergraduate students. $\mathrm{He}$ has a national research connection with different research organizations of Bangladesh and has several publications in the field of Food and Nutrition. The research interests of the author are child obesity, anemia, micronutrient deficiency and effect of excessive drug use on health and its prevention. 


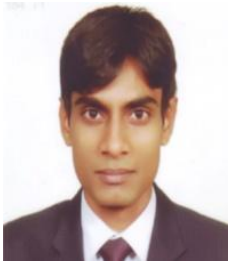

The author is a Lecturer in the department of Food Technology and Nutritional Science of Mawlana Bhashani Science and Technology University, Bangladesh. He has completed four years graduation B.Sc with honors and M.Sc in Applied Nutrition and Food Technology from Islamic University, Bangladesh with First Class. He has almost 1 years of teaching. He has a national research connection with different research organizations of Bangladesh and has several publications in the field of Food and Nutrition. The research interests of the author are development of functional food, anemia, micronutrient deficiency and effect of excessive drug use on health and its prevention

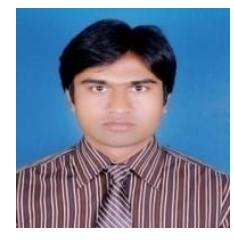

The author has completed four years graduation B.Sc with honors and MS in the department of Food Technology and Nutritional Science of Mawlana Bhashani Science and Technology University, Bangladesh. He has received different training form different departmental and national workshops and conferences. He is very keen to learn scientific research in the field of Food and Nutrition

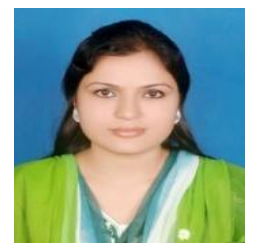

The author is a Research assistant in the department of Biochemistry and Cell Biology of Bangladesh University of Health Sciences, Bangladesh. She has completed four years graduation B.Sc with honors and MS in Food Technology and Nutritional Science from Mawlana Bhashani Science and Technology University, Bangladesh with First Class and front position. She has received different training from different departmental and national workshops and conferences. She is very keen to learn scientific research in the field of Food and Nutrition

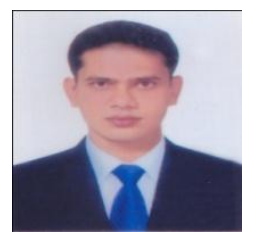

The author has completed four years graduation B.Sc with honors and M.Sc in Applied Nutrition and Food Technology from Islamic University, Bangladesh. Now he is working as Nutritionist at BIRDEM General Hospital Shabagh, Dhaka for 4 years. He does patients counseling and preparation of diet chart in diabetic and nondiabetic patients. The research interests of the author are development of functional food, anemia, micronutrient deficiency and effect of excessive drug use on health and its prevention

\section{LIST OF FIGURE AND TABLES}

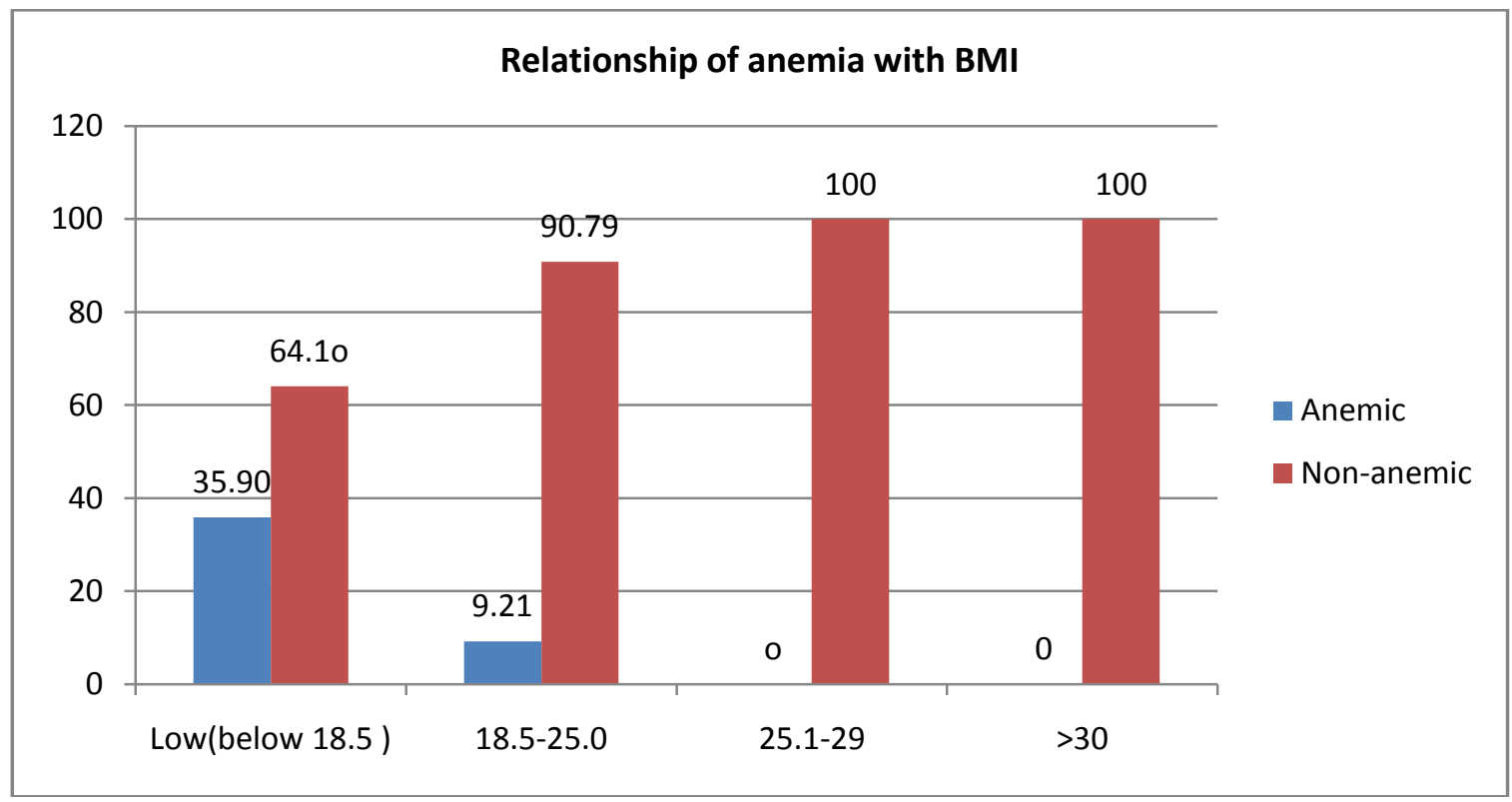

Results are express as (percentage), number; $* \mathbf{P}<\mathbf{0 . 0 5}$ show the significant results, $\chi \mathbf{2}=\mathbf{1 6 . 0 2 0}$.

Fig 1: Relationship of anemia with Body Mass Index

Table 1: Socio-demographic features of the respondent

\begin{tabular}{|l|l|l|l|}
\hline Variables & Categories & Frequency & Percentage \\
\hline \multirow{4}{*}{ Age } & 12 years & 15 & 12.5 \\
\cline { 2 - 4 } & 13 years & 30 & 25.0 \\
\cline { 2 - 4 } & 14 years & 37 & 30.8 \\
\cline { 2 - 4 } & 15 years & 22 & 18.3 \\
\cline { 2 - 4 } & 16 years & 14 & 11.7 \\
\cline { 2 - 4 } & 17 years & 2 & 1.7 \\
\hline
\end{tabular}




\begin{tabular}{|c|c|c|c|}
\hline \multicolumn{4}{|c|}{ Mean age (years): $13.9667 \pm 1.230$ SD; Min: 12 years; max: 17 years } \\
\hline \multirow{3}{*}{ Parents education } & Both illiterate & 37 & 30.83 \\
\hline & Single literate & 51 & 42.50 \\
\hline & Both literate & 32 & 26.67 \\
\hline \multirow{4}{*}{ Family members } & Up to 3 members & 14 & 11.6 \\
\hline & 4-5 members & 41 & 34.2 \\
\hline & 6-7 members & 44 & 36.7 \\
\hline & $>8$ members & 21 & 17.5 \\
\hline \multirow[t]{2}{*}{ Types of family } & Nuclear & 76 & 63.3 \\
\hline & Joint & 44 & 36.7 \\
\hline \multirow[b]{4}{*}{ Hemoglobin level } & Non anemic $h b: \geq 11$ & 99 & 82.5 \\
\hline & Mild anemia hb: $10-10.9$ & 13 & 10.9 \\
\hline & Moderate anemia hb:7-9.9 & 7 & 5.8 \\
\hline & Severe anemia hb: $<7$ & 1 & 0.8 \\
\hline \multicolumn{4}{|c|}{ Non anemic $82.5 \%$ Anemic $17.5 \%$} \\
\hline \multirow{2}{*}{$\begin{array}{l}\text { Knowledge on iron } \\
\text { deficiency anemia }\end{array}$} & Yes & 17 & 14.2 \\
\hline & No & 103 & 85.8 \\
\hline
\end{tabular}

Table 2: Relationship of anemia with certain condition of the respondent

\begin{tabular}{|c|c|c|c|c|}
\hline & Categories & $\begin{array}{l}\text { Percentage of } \\
\text { anemic, } n=21\end{array}$ & $\begin{array}{l}\text { Percentage of non- } \\
\text { anemic, } n=99\end{array}$ & Statistics \\
\hline \multirow[b]{2}{*}{ Family types } & Nuclear & $7(9.21)$ & 69(90.79) & \multirow{2}{*}{$\begin{array}{l}\chi^{2}=10.559 \\
p=0.014\end{array}$} \\
\hline & Joint & $14(31.82)$ & $30(68.18)$ & \\
\hline \multirow{4}{*}{ Family members } & Up to 3 & $1(7.14)$ & $13(92.86)$ & \multirow{4}{*}{$\begin{array}{l}\chi^{2}=17.231 \\
p=0.045\end{array}$} \\
\hline & $4-5$ & $4(9.76)$ & $37(90.24)$ & \\
\hline & $6-7$ & $4(18.18)$ & $36(81.82)$ & \\
\hline & $>8$ & $8(38.10)$ & $13(61.90)$ & \\
\hline \multirow{5}{*}{ Monthly income } & $<6000$ & $2(66.67)$ & $1(33.33)$ & \multirow{5}{*}{$\begin{array}{l}\chi^{2}=42.465 \\
p=0.000\end{array}$} \\
\hline & $6000-10000$ & $8(20.0)$ & $32(80.0)$ & \\
\hline & $10001-15000$ & $8(14.55)$ & $47(85.55)$ & \\
\hline & $15001-20000$ & $3(15.0)$ & $17(85.0)$ & \\
\hline & $>20000$ & $0(0)$ & $2(100)$ & \\
\hline \multirow{3}{*}{ Literacy status of parents } & Both illiterate & $13(24.53)$ & $40(75.47)$ & \multirow{3}{*}{$\begin{array}{l}\chi^{2}=16.020 \\
p=0.021\end{array}$} \\
\hline & Single literate & $7(17.94)$ & $32(82.05)$ & \\
\hline & Both literate & $1(3.57)$ & $27(96.43)$ & \\
\hline \multirow{3}{*}{ Duration of Blood flow } & 2 to 3 days & $2(7.40)$ & $25(92.59)$ & \multirow{3}{*}{$\begin{array}{l}\chi^{2}=11.589 \\
p=0.072\end{array}$} \\
\hline & 4 to 5 days & $8(12.90)$ & $54(87.10)$ & \\
\hline & $>5$ days & $11(35.48)$ & $20(64.52)$ & \\
\hline \multirow[t]{3}{*}{ Milk/milk based food } & Daily & $1(4.76)$ & $38(38.39)$ & \multirow{3}{*}{$\begin{array}{l}\chi^{2}=19.934 \\
p=0.018\end{array}$} \\
\hline & Weekly & $7(33.33)$ & $42(42.42)$ & \\
\hline & Monthly & $13(61.91)$ & 19(19.19) & \\
\hline Fruits & Daily & $4(19.05)$ & $20(20.20)$ & $\chi^{2}=18.711$ \\
\hline
\end{tabular}




\begin{tabular}{|l|l|l|l|l|}
\hline & Weekly & $5(23.81)$ & $55(55.56)$ & $\mathrm{p}=0.028$ \\
\cline { 2 - 4 } & Monthly & $12(57.14)$ & $24(24.24)$ & \\
\hline Green leafy vegetables & Daily & $3(14.29)$ & $55(55.56)$ & $\begin{array}{l}\chi^{2}=26.069 \\
\mathrm{p}=0.003\end{array}$ \\
\cline { 2 - 4 } & Weekly & $7(33.33)$ & $35(35.35)$ & \\
\cline { 2 - 4 } & Monthly & $11((52.38)$ & $9(9.09)$ & \\
\hline
\end{tabular}

Table 3: Nutritional Intake of Respondents as per 24 Hours Dietary Recall

\begin{tabular}{|c|c|c|c|c|c|}
\hline Nutrients & Age in years & $\begin{array}{l}\text { Anemia } \\
\text { Mean } \pm \text { SD }\end{array}$ & $\begin{array}{l}\text { Normal } \\
\text { Mean } \pm \text { SD }\end{array}$ & RDA & P-value \\
\hline \multirow{6}{*}{$\begin{array}{l}\text { Calories } \\
\text { (kcal) }\end{array}$} & 12 & $1535 \pm 53$ & $1641 \pm 189$ & \multirow{5}{*}{ 2060kcal/day } & 0.523 \\
\hline & 13 & $1523 \pm 479$ & $1649 \pm 192$ & & 0.646 \\
\hline & 14 & $1465 \pm 325$ & $1636 \pm 158$ & & 0.098 \\
\hline & 15 & $1576 \pm 253$ & $1651 \pm 292$ & & 0.699 \\
\hline & 16 & $1531 \pm 311$ & $1606 \pm 244$ & & 0.241 \\
\hline & Overall & $1592 \pm 293$ & $1622 \pm 255$ & & \\
\hline \multirow{6}{*}{$\begin{array}{l}\text { Iron } \\
(\mathbf{m g})\end{array}$} & 12 & $5.19 \pm 1.83$ & $8.93 \pm 4.72$ & \multirow{4}{*}{$28 \mathrm{mg} / \mathrm{day}$} & 0.042 \\
\hline & 13 & $5.10 \pm 1.93$ & $8.72 \pm 4.52$ & & 0.037 \\
\hline & 14 & $5.38 \pm 1.64$ & $7.03 \pm 2.84$ & & 0.048 \\
\hline & 15 & $5.11 \pm 1.93$ & $7.14 \pm 3.32$ & & 0.010 \\
\hline & 16 & $5.21 \pm 4.29$ & $6.55 \pm 5.11$ & $30 \mathrm{mg} / \mathrm{day}$ & 0.086 \\
\hline & Overall & $5.21 \pm 3.31$ & $7.05 \pm 3.96$ & & 0.035 \\
\hline
\end{tabular}

